\title{
CIÊNCIA'NATURA
}

\section{Evaluating girls students dormitories with an emphasis on comfort and intimacy}

\author{
Mohsen Kameli ${ }^{1}$, Maryam Fakhri ${ }^{2}$ and Maryam Mohammadi ${ }^{3}$ \\ 1 Young Researchers and Elite Club, Qom Branch, Islamic Azad University, Qom, Iran \\ 2,3 Young Researchers and Elite Club, Tafresh Branch, Islamic Azad University, Tafresh, Iran
}

\begin{abstract}
Many researches, performance in the field of social behavior, have evaluated the issue of intimacy along with culture, religion and environment, intimacy is very important in girls dormitory; the issue of intimacy, as a principle dominating all aspects of life, has beautifully been introduced and discussed in Iranian architecture. The factor of being Iranian integrated with Islamic culture, art and thought, as given a new feature to Iranian art. The present research aims to study student dormitories with the emphasis on comfort $\mathcal{E}$ intimacy. The research method is descriptive - analytic based on surveys; and the technique is using questionnaire. The statistical population is the students living in the city of Tafresh with 300 samples selected purposefully. According to the results, the variables of comfort and intimacy not only can be useful for the security of girls hostel, it also can affect the relationships of the students with outside the dormitory and their comfort inside the dormitory. Regarding the component of intimacy in designing dormitory, it possible to create maximum spaces inaccessible to others; building unroofed, cozy and open spaces helps students to reside in this place for longer time, and to feel safety in this environment as their own home. Comfort and intimacy are of mutual relations; the more you consider the principles of intimacy, the more the girls of hostel feel comfortable.
\end{abstract}

Keywords: girls, comfort, intimacy, students dormitory, safety. 


\section{Introduction}

\section{Statement of the problem}

In different countries, student hostel are considered as physical head quarters, residential buildings and areas of campus which are intended for living, comfort, providing students mental health along with utilizing other cultural facilities, welfare, curriculum, physical education counseling, Library, nutrition, health and treatment according to the current regulations. Considering the fact that the importance of dormitories is the social duties of education, these places are governed by all disciplinary and administrative rules of university (Karimpour fard 2005:2). Emphasizing on intimacy is one of the foremost factors in girls dormitories, the issue of intimacy as a principle dominating all aspects of life is beautifully and artistically introduced and discussed in Iranian architecture. The factor of being Iranian combined with Islamic culture, art and reflection has given a new feature to Iranian art. Given many studies conducted in the area of social behavior, the issue of intimacy is evaluated along with culture, religion and environment. Altman (1984), on the other side, considers intimacy or privacy as temporary isolation of human from public environment through ownership rules, he believes that changes in human conditions happen in public and private places through inherent distinctiveness of these two environments. (Newell 1995:98)

In dormitories, professional architectures in the field of Islamic principles emphasis three intimacy providing factors, including doors, windows, shutters, height of the walls and curtains (Hakim 1969: 64). Other elements which must be considered in designing girls hostels are comfort, crowd and being at home, the significant elements which must be considered in designing girls hostles are comfort, crowd and being at home, the significant elements felt by students according to their situations at home. Some research has been performed on mental health and sleep quality of the students living in dormitories. The results suggest that there is a direct and significant relationship between sleep quality and mental health of the students residing In dormitory. (Mohammadi Farakhran et al 2012) giving information which identify and remove welfare shortage in dormitories is a considerable help to in charge officials, develop student's mental and spiritual state and prepare them to participate in society and to accept responsibility: today, places such as girls dormitory pay less attention to intimacy and comfort needed for female students. They more consider functional and performance aspects for students but can students achieve the desired comfort in a place which lacks welfare facilities in terms of intimacy principles?

The need for research

There have been some quantitative and qualitative studies to achieve the requirements and remove the shortages in the dormitories, In quantitative part we can get better results by questionnaire. Reviewing the studies, it becomes clear that a series of rules and regulations must be considered for students mental, spiritual and physical health. These rules must certainly be observed; if the residents of hostels do not obey the rules, it will result in some specific problems. Thus, in order to have an ideal dormitory, you must not only study it in terms of design but you must also enforce your special rules through in charge officials of the place. Reviewing the case samples, we realize that we can build an ideal space (place) to improve students intellectual levels; a fun and pleasant place where encourages students to express their ideas, and enjoys the architectural levels; a fun and pleasant place where encourages students to express their ideas, and enjoys the architectural elements as this feature of intimacy. The influential elements which intensify this feature of intimacy are: sense of comfort, of crowd, of enjoying privacy, of opportunity etc.

According to the currents needs, some suggestions have been given to create intimacy in whole or part of girls hostel as physical design of students living place and to build architectural components. With regard to the factor of intimacy, doing research is necessary to eradicate destructive effect of visual disturbances of the hostel on students. Identifying and removing shortages in facilities along with making balance and coordination, students realize positive visual effects of dormitory studying religious beliefs among students we can understand their relative values of beliefs which has established the main role of beliefs in intimacy in dormitories; and thus we can organize the intended design and rules for girls hostels. Easily in other words, is 
also important and necessary to preserve the principle of intimacy and to create mental and physiological comfort for female students in student dormitory. The need for security in a student residence can be a part of components of intimacy; why does security in hostel cause students mental comfort; why does it build an ideal place through maintaining dignity and values among students in dormitory. Creating a cozy and calm place leads to keeping privacy and respect among students welling in dormitories. Emphasizing on two concepts: the concept of avoidance meaning to keep distance and to reduce means of communication with other people, and the concept of in proximity meaning to increase the possibility for more action and interaction with others and their feasibility in man-made environments, this frame work beings to suggest an anthropological approach. (Mahdavinejad, Mashayekhi 2010) Observing and maintaining privacy is a mutual relationship which can include the relationship between two individuals, a person with a group, family or other social cores, or a relationship between to different cores that happens in a special place and special time. Building a healthy physical place is another requirement which can be considered for dormitories. This physical place refers to a place for students sports, a place where students can regularly use sport equipments; in this way, they are encouraged to do different sports and to participate in competitions the result from the studies show that how design, intimacy, comfort, security and removing destructive effects can be used to create sublimating spaces. A place where provide students with pleasant and enjoyable space and help them experience their situations and positions in different ways.

\section{Research objectives}

In general, the goals of the research are as follow:

a) To improve the level of female students lives in accordance with intimacy principles which result from the effects of dormitory environment. b) To improve student's learning level regarding the facilities \& welfare in students dormitory

c) To provide students comfort, to enhance the level of students mental and physiological peace, and to achieve positive visual effects in dormitory from students perspective

\section{Research Questions}

According to aforementioned objectives, the following questions are raised:

a) How can special arrangement of dormitories be considered in terms of comfort components?

b) How secure is girls hostel according to its indexes?

c) How intimate is girl hostel in accordance with its indexes?

Research background

Many papers have been written on dormitories and intimacy; however, each of them has separately been dealt with. For examples Ali Ebadi (2010) reviews a paper entitled "studying psychological indexes of environment in designing student dormitories." There is a significant relationship between psychological indexes and gender (sex), educational grade, and type of student dormitory. In fact, sex, educational grade and type of student dormitory are among those elements which must necessarily be regarded since these elements effect some of the students psychological indexes including sense of comfort, sense of congestion, privacy, opportunity and territory-seeking, feeling at home etc.

Jihad Daneshgahi research Deputy, Tehran branch(2005) published a paper entitled "Designing girls schools with Regard to intimacy and comfort. Considering the need for intimacy and privacy in whole or part of girl's schools, the research aims to ideal with the physical design of educational sites and for building architectural components; all are used both to reconstruct the current schools and to build the new schools.

Everett(2011) has written a paper entitled "Authorities of dormitories as law executors." This study has been done in a quantitativequalitative method; quantitative part is done by using questionnaire for which 32 officials of dormitory are selected and questioned. The results demonstrate a friendly relationship between the authorities with under-graduate degree and students. However, there is some infractions when the rules of dormitory are violated by a dormitory dweller, and there is conflict between authorities and students as a result. 


\section{Research Methodology}

The present research type is functional and its methodology is descriptive- analyticalquantitative. The population of the research is all students who are living in dormitory in the city of Tafresh (In Iran). A purposeful method is used to achieve sample size is determined by Cochran techniques. (Hafez nia2011:78). To do this, 300 questionnaires are distributed among dormitorydweller students. In order to collect information, we have used library and archive (documentary) resources as well as field study. The components of comfort and intimacy are evaluated by library resources; and the levels of comfort and intimacy in dormitories of sample population are measured by field study (questionnaire technique). To clarify data, first the normality of data is examined; and then, the research variables of one-sample t-test and two-sample $t$ test are measured by SPSS 20 software.

\section{Theoretical basis}

Designing girl's hostel with regard to comfort creating mental health in students dormitory has a close relation with preparing requirements for students comfort, Mental health, ability to make a harmonious relationship with others, modifying individual and social environment, conflict resolution and personal desires fairly and reasonable, (Milani, 1995:15) in other words, mental health means compromising with environment as much as possible; so that it thoroughly leads to happiness and useful perception.(Rajabi, 2007:24) according to the psychiatrists, a healthy person is the one who can control his/her behavior while facing social problems; in other words, he/she is study enough while be involved in biological, psychological and social activities. But a psycho analyst believes that mental health is the ability to make compatibility between institution and commands, and to use defense mechanisms when facing severe psychological trauma (Rajabi, 2007:147)

\section{The components of comfort}

Interior space of dormitory or dormitory's shape: regarding it's accessibility, corridors, rooms, kitchen and garbage collection system, interior space of dormitory can be an ideal form in terms of spaces and location; in this way, it can create a comfortable visual connection with environment and thus can symbolize comfort.
The yard of hostel and access to its outside due to the mutual relationship between dormitory's security and comfort, girl's students comfort can be provided and maintained by correct design of green places and locations outsides the hostel, by separate entrances for male visitors, by surveillance cameras, by lightening in the yard and open spaces. Comfort not only can provide students' welfare, it can also help them with security it creates. (www.pezeshki.us)

\section{Dormitory's Security}

Girl's hostel security it very important for girl's students, because feeling secured helps them feel comfort, therefore, they can spend their time without stress and so they can reach maturity and peace of mind. Security is one of the most natural and necessary needs of human beings. According to Maslow, the spiritual father of humanism in psychology, the need for security is one of infrastructure needs for growth and developments of human personality if this need is not satisfied, character development is disturbed(Rajabi, 2007:104)

University and Students are scientific, cultural and social development axis of the country; and student's hostel, as their second home, is of special importance in promoting spiritual vitality, creating and maintaining mental and physical comfort, developing thought and reflection, promoting individual character and enhancing students educational quality. In order to facilitate and improve quality of life in student's hostel, it is necessary to codify effective and transparent rules and relationships regarding individual and collective rights, to reinforce the spirit of responsibility and selfconfidence, to provide students with security and to regulate their stay in dormitory. Generally, security is one of important features for every residential environment it includes such nations as security in face of natural and unnatural disasters, security against the invasion of other social groups, and security against the effects of human activities, etc. This nation becomes important for a student who has always lived in family safe place, and has never experienced living in a strange place and away from family support. So in this new place, he/she sees the university as the only support (safe place); he/she also finds dormitory as a part of facilities of university; that comparing with other 
places, it seems to be more secure and familiar. $\mathrm{He} / \mathrm{she}$ has a sense of belonging to this place; this feeling can be the result of complete and thorough management surveillance of university over dormitories. In addition to abovementioned benefit and advantages, there are a variety of things which make dormitory enjoyable and attractive for students. These things are the happiness due to sense of living with peers, specificity of building(the place); belonging to a group of students as well as a sense of satisfaction of getting away from family.

Designing girl's hostel regarding the issues of intimacy

Designing girls hostel with regard to intimacy divides into two parts: Designing the overall size of the building and designing the components and elements of the place including the design of corridors, private corners, walls and windows. Since these patterns aim to triggers designer's minds, it has avoided to approach to objective physical images. Introducing the principles and classifying different types makes it possible for the designers to face with this subject in each part in this way they will be able to solve the problem. Worth mentioning that these patterns can never been used directly and they can only be selected and utilized through analyzing various components such as climate, environmental features and sites, different perceptions, and domination, operational issues, etc. the individual samples introduced at the end of each part aims to present how any of these diagrams can lead to a design. In fact, these samples are designed to show capability of various types of design from a diagram not to determine the design final response.

The role of student's hostel in university's goals

Today, this feat is ignored that although the universities have to educate student's, they have to faster students characters to prepare them for entering society and for making them accept social responsibilities (Mirheidar 1994). In other words, the university should be a place where the students are trained to be absorbed and be active in society. The university should not only faster student's intelligence and technical knowledge and information, they should also be a place where train and educate students for being absorbed and active in society. Therefore, student can reach a complete self-flourishing in all aspects of life. On the whole, it can be said that university must deeply consider the following feature:

a) To improve human competency for living with others;

b) To educate and direct human empathy and emotions;

c) To create and support students autonomy, independence and self-governments;

d) To faster and illuminate goals of students' lives; and

e) To create a sense of integration and unity between students and a large community which they are living in (Dr. Tousi, 1994).

If we accept such goals for universities, then classes, halls, institutional services, library, laboratory of universities and above all the student's hostels will become a place for human education in whole life; and in this way, university from and configuration can be build according to its goals and mission.

Merely Dealing with educational problems and research without considering cultural infrastructures can never solve fundamental problems. In fact, scientific structure are frequently related with cultural structure; and they both affect each other's performance. Student hostel should be considered as a component (part) of university educationalcultural complex. A place that according to its student-residential nature is related to urban residential areas in one hand, and to university campus in the other. Furthermore, student's hostels can be seen as one of the important cultural centers for interacting and enriching various experiences and knowledge. Therefore, regarding the relation between these places and university cultural environment their facilities must be appropriate with the facilities of a cultural and educational environment on the one hand, the formation of associations, cultural, religious, social, art literary organizations in universities as well as student's dormitories and recruitment among student will be filling their leisure time \& on the other hand considering students' favorite activities help them more tolerate problems and shortages of environment and so make them better adapt to conditions (Tabrizi, 2000).

The advantages of using student's dormitory 
It less happens that non-native student do not prioritize living in hostel when s/he choose a place for staying during staying at university. In spite all problems students have while living in hostel, there are some benefit that attract the students attention. These benefits can be studied from two points of view, economy and security, Economy crisis is one of young hood aspect most of the youth face with. Thus, there are some factors such as having a relatively low cast place to live and taking advantage of university cheap food, that make dormitory better than more interesting place for the students who have not reached financial independence yet and are still dependents of their parents, and also those students whose families are financially weak. In other words, being more affordable, staying in student's dormitory impose lower cost of living upon students.

\section{Girl's Dormitory}

Non-resident student accommodation in dormitory is allowed only with the consent of host roommates and written authorization of the dormitory administration. In girls' hostels, the male visitor must be one of the girl's first degree blood relatives; he must show his valid ID card to hostel shift supervisor then fill in and sign the special meeting from or the related note. In girl's hostel, husband needs to show his ID to the hostel shift supervisor when he wants to meet his wife. ID card is needed but it is not enough. Hostel shift supervisor has to compare the profile of the male visitor with the student's close relatives identification already recorded in the special form; then he must prevent meeting and report to the chief of hostel administration in case of any contradiction. All visits will be in a public hall or a place which is determined for such a purpose. Hostel General silent hours is determined and announced according to the seasons and hostel's conditions. All residents of hostel, including staff hostel's officials and students, must observe the contains of this regulation. If anyone violates or acts against these rules, they will be referred to legal authorities of university (Mirzaee 2000).

The psychology of environment in

\section{designing dormitory}

In short, environmental psychology deals with the study of type and way of human interaction with environment. In other words, environmental psychology is a branch of psychology which studies the nature of the relationship of individual with his/her environment(Rosel 2009). This science studies individual cognitive function in relation with environment, and follow environmental priorities, values and meanings. Due to operational quality and importance of theoretical finding in this field when basic concepts of environmental psychology developed by such thinkers as Barker and Hall, environmental psychology entered the field of designing and was applied in professions such as architecture, interior design, planning and urban design, in manmade places, we can utilize findings of environmental psychology in some case such as huddle and crowed, noise and private places. This branch of contemporary psychology provides a framework of perspectives, insights, research and hypothesis that help people better understand and perceive the mutual relationships (interaction) between human being and his environment using this knowledge, evaluation, as the best tool for designers in various professions, can be done before designing and building. Environmental psychology studies behaviors in a framework of physical camp (headquarter). Physical headquarter means a physical place which is applied with defined organizational and operational purposes. For example, a hospital where the patients are examined and treated; or a class where students are taught and educated. Since it is assumed that human behaviors and experiences cannot be studies without separately considering environmental situations, physical camp (head quarter) means that according to environmental psychology, human him-self is one of the factors that forms environment. Behavior headquarters or places should not be too crowded; that is, the number of people must be appropriate with current behavioral patterns; and people should enjoy their enough private space and control their ideal territory (Karimpour Fard 2007).

\section{The components of Intimacy \\ The overall size of building}

The basic design of dormitory building and the idea of overall volume (size) can have a great impact on providing intimacy in dormitory. At the beginning of designing, dormitory site must carefully be analyzed and the dominating factors 
must be identified. While analyzing, you should pay attention that not only the current condition of the place (area) is the criteria of identification but also comprehensive (master) and detailed plans as well as predicted conditions of the area where dormitory is located must be observed. With regard to this dominating factors, you should also pay attention to distance, to type of domination and access, and to height of domination/accessing factor because each of these elements can influence on choosing better scheme for building and intimate hostel.
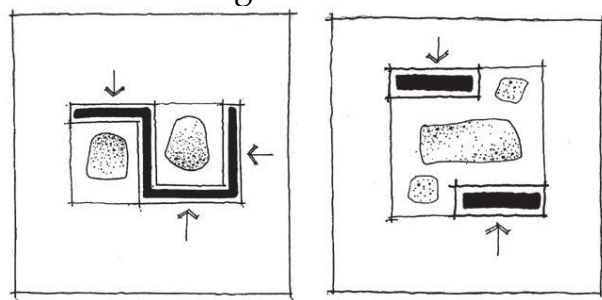

Figure 1 - Green size space according to the formation of building

\section{Private/cozy corners}

In many urban sites and areas, It is hardly possible to create intimacy for all open places and for the courtyard of dormitory. Therefore, we can make intimate and private only some limited places where students can spend some hours of their free time and feel comfort and safe. Such private corners can be predicted and designed in various models and conditions to meet these needs of students in their leisure.
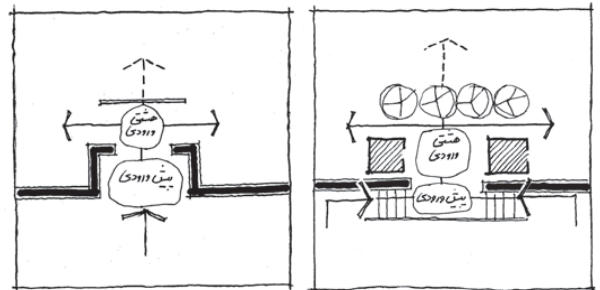

Figure 2 - building entrance with regard to intimacy

\section{Entrances}

In designing girl's hostel entrance, we should regard those issues which affect it formation. Having a space before entrance is one of the main and necessary factors for entrance; it provide students with a place where facilitates their gathering while entering and living the hostel. Considering their importance and usage, these pre-entrance (or corridors) are not only build in hostels but also in must building. In Iranian architecture, we can see the corridors (that are called open part; that is, making an opening space in texture).

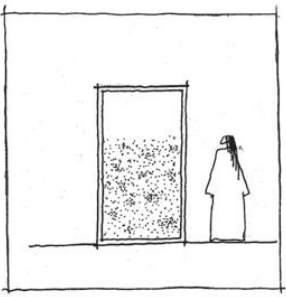

Figure 3 - the location of entrance with regard to green space

\section{Windows}

The lack of intimacy is when the hostel is visible through the windows. In fact, to make the hostel private it is necessary to limit visibility through windows. The quality of interior space and light always prioritize hostel intimacy. Therefore, the strategies of intimacy-making for windows should never deprive students of having direct and frequent connection with outside the hostel and sufficient light.
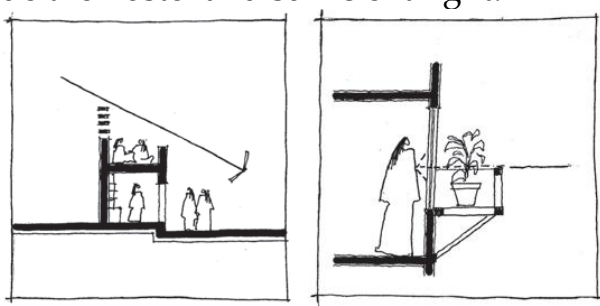

Figure 4 - the location of window considering the stairs, intimacy and students' activities

\section{Walls}

Wall is one of the main factors which can create intimacy for open spaces of the hostel since privacy/intimacy of hostel's open spaces is the major component for building a private intimate place, factors such as materials, form, and physical quality of the wall must be considered while designing heightening the walls is the main way to provide open spaces of dormitory with intimacy (research Deputy of Jihad Daneshgahi, Tehran branch 2005).

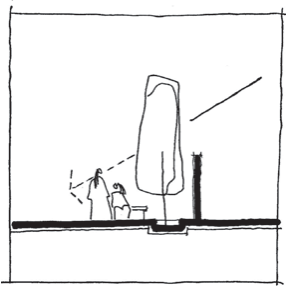

Figure 5 - planting trees besides the walls in order to create privacy 


\section{Research Finding}

Ranking statistical population and its characteristics for different ages and frequency distribution of education are as follow:

Figure 9 show that $63 \%$ of respondents have got their BA/BS and $37 \%$ of respondents have got their MA/MS. The average age of respondents is 23.46 and the standard deviation is 3.764 .

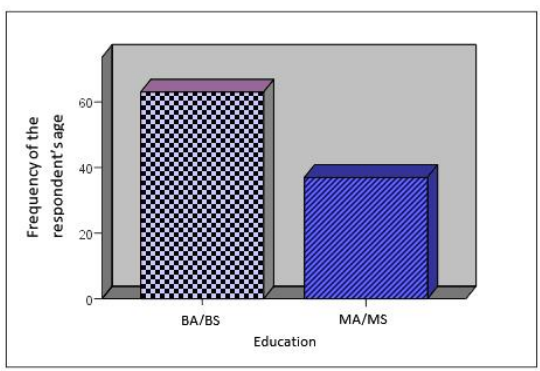

Figure 9 - the diagram of the frequency of respondent's education

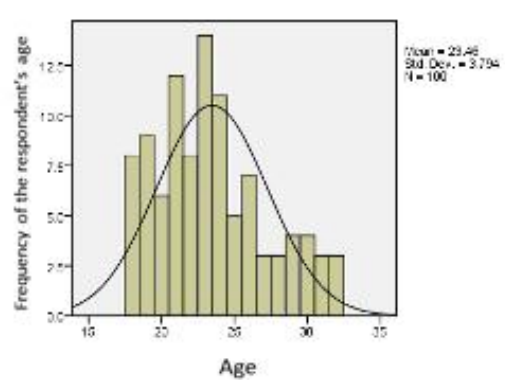

Figure 10 - the Histogram of the respondent's age

Source: Research Finding

Figure 11 shows that $64.5 \%$ of respondents believe that height of the windows highly affects an intimacy. $60.7 \%$ of respondents also believe that courtyard of dormitory hardly undermine the hostel intimacy. $68.4 \%$ believe that windows' guard/Fence is really important and effective for keeping security of students.

Finally, $4.44 \%$ of respondents claims that lighting has negligible impact on security.

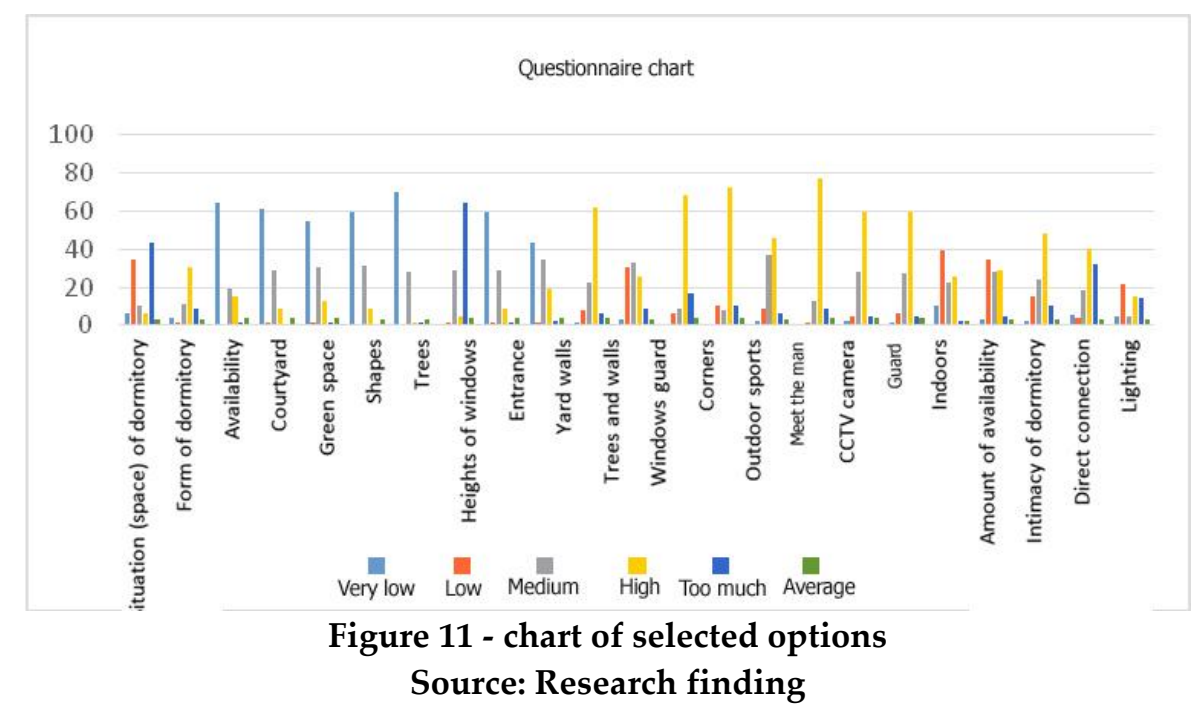

Ranking statistical population and its characteristics for security, intimacy and percentage of selected options, in general, are as follow:

According to table 1 , the mean of security component (variable) is 3.0036, is standard deviation is 0.362 , the mean of intimacy component (variable) is 2.962 and its standard deviation is 0.372 .
Table 1 - mean and standard deviation of research variables

\begin{tabular}{c|c|c}
\hline & Mean & Standard \\
\hline Security & 3.0036 & 0.362 \\
\hline Intimacy & 2.962 & 0.372 \\
\hline \multicolumn{3}{c}{ Source: Research Finding }
\end{tabular}

\section{Question 1:}

How can we consider spatial arrangement used in the hostel with emphasis on comfort variables? 
According to table 2, in order to answer the question, the hostel spatial arrangement regarding the issue of comfort is as follow:

The shape and form of dormitory make no difference; green space can eight her exist or not however it has impact on keeping comfort; shapes can be build; guards are necessary for windows; open space for sports is not suggested for girl's hostel; it is necessary to build a place for male relative visitors; CCTV camera should be installed; to enjoy comfort, spatial intimacy must be regarded; lighting is not very important.
Table 2 illustrates that for $64.5 \%$ of respondents, the height of dormitory windows is highly important for intimacy. $60.7 \%$ of respondents believe that having courtyard can rarely endanger the hostel privacy/intimacy. To $3.94 \%$ of respondents windows guards have a great impact an students' security. Finally, $4.44 \%$ of respondents see lighting as less important element in keeping security.

Table 2 - percentage of selected options

\begin{tabular}{c|c|c|c|c|c|c|c}
\hline \multirow{2}{*}{ Number of questions } & \multirow{2}{*}{ Questions } & \multicolumn{5}{|c}{ Percentage of selected options } \\
\cline { 2 - 8 } & & Very little & Little & Medium & Much & Very much & Ranking average \\
\hline 1 & Dormitory space \& environment & 6.3 & 34.2 & 10.2 & 6.3 & 43 & 3.16 \\
\hline 2 & Form of dormitory & 48.1 & 1.3 & 11.4 & 30.3 & 8.9 & 3.22 \\
\hline 3 & Access to main entrance & 64.5 & - & 19 & 15.2 & 1.3 & 3.84 \\
\hline 4 & Having courtyard & 6.7 & 1.3 & 29.1 & 8.9 & - & 4.10 \\
\hline 5 & Green space & 54.3 & 1.3 & 30.4 & 12.7 & 1.3 & 4 \\
\hline 6 & Shapes & 59.5 & - & 31.6 & 8.9 & - & 3.18 \\
\hline 7 & Tall trees & 69.6 & - & 27.8 & 1.3 & 1.3 & 3.13 \\
\hline 8 & Height of windows & - & 1.3 & 29.1 & 5.1 & 64.5 & 4.17 \\
\hline 9 & Tall trees instead of curtain & 59.5 & 1.3 & 29.1 & 8.8 & 1.3 & 4.06 \\
\hline 10 & Separate entrance & 43 & 1.3 & 34.2 & 19 & 2.5 & 3.87 \\
\hline 11 & Courtyard walls & 1.3 & 7.6 & 22.8 & 62 & 6.3 & 3.64 \\
\hline 12 & Trees and wall for the corners & 2.5 & 30.4 & 32.9 & 25.3 & 8.9 & 3.07 \\
\hline 13 & Guards of windows & - & 6.3 & 8.9 & 68.4 & 16.5 & 3.94 \\
\hline 14 & Corners and cozy places & - & 10.1 & 7.6 & 72.2 & 10.1 & 3.82 \\
\hline 15 & Open spaces for sports & 2.5 & 8.9 & 36.7 & 45.6 & 6.3 & 3.44 \\
\hline 16 & Male visitors & - & 1.3 & 12.7 & 77.2 & 8.9 & 3.93 \\
\hline 17 & CCTV camera for intimacy & 1.3 & 7.6 & 21.5 & 62 & 7.6 & 3.67 \\
\hline 18 & CCTV camera for security & 2.5 & 5.1 & 27.8 & 53.2 & 11.4 & 3.65 \\
\hline 19 & Guards & 1.3 & 6.3 & 27.8 & 59.5 & 5.1 & 3.60 \\
\hline 20 & Indoors & 10.1 & 39.2 & 22.8 & 25.3 & 2.5 & 2.70 \\
\hline 21 & Availability & 3.8 & 34.2 & 27.8 & 29.1 & 5.1 & 2.97 \\
\hline 22 & Intimacy which Influences security & 2.4 & 14.9 & 24.1 & 48.2 & 10.4 & 3.3 \\
\hline 23 & Direct connection & 5.3 & 4.2 & 18.3 & 40.1 & 32.1 & 3.4 \\
\hline 24 & Lighting & 44.4 & 21.4 & 4.6 & 15.1 & 14.5 & 3.03 \\
\hline
\end{tabular}

\section{Question2:}

How much is the hustle security with regard to its indexes?

Table3, shows that according to the given significance level which is 0.01 in the below table, and based on its comparison with allowed error value which is 0.5 , we can conclude with $95 \%$ confidence that since mean difference is positive, the level of dormitory security is more than the medium level in mentioned indexes.

Table 3 - T single test for security samples

\begin{tabular}{c|c|c|c|c}
\hline Variables studied & number & mean & Standard deviation & Standard deviation from the mean \\
\hline & 300 & 3.0036 & 0.362 & 0.0362 \\
\hline Security & Statistical t values & Degree of freedom & The significance level & Difference from mean \\
\hline & 0.1 & 99 & 0.01 & 0.082 \\
\hline
\end{tabular}




\section{Question 3:}

How much is the girl's hostel security maintained if we consider its intended indexes?

Table4 indicates that according to the given significance level which is 0.31 in table (4) and comparing it with allowed error values which is 0.05 , we can conclude with $95 \%$ confidence that since the mean difference value is positive, the hostel intimacy level is higher than the medium level in the mentioned indexes.

Table 4 - T single test for intimacy samples

\begin{tabular}{|c|c|c|c|c|}
\hline $\begin{array}{c}\text { Variable } \\
\text { s studied }\end{array}$ & Number & Mean & $\begin{array}{l}\text { Standard } \\
\text { deviation }\end{array}$ & $\begin{array}{c}\text { Standard } \\
\text { deviation } \\
\text { from the } \\
\text { mean }\end{array}$ \\
\hline & 300 & 2.962 & 0.372 & 0.0373 \\
\hline \multirow[t]{2}{*}{ Intimacy } & $\begin{array}{l}\text { Statistica } \\
1 \mathrm{t} \text { values }\end{array}$ & $\begin{array}{l}\text { Degree } \\
\text { of } \\
\text { freedo } \\
\mathrm{m} \\
\end{array}$ & $\begin{array}{c}\text { The } \\
\text { significanc } \\
\text { e level }\end{array}$ & $\begin{array}{c}\text { Differenc } \\
\text { e from } \\
\text { mean }\end{array}$ \\
\hline & 0.01 & 99 & 0.031 & 0.0376 \\
\hline
\end{tabular}

\section{Conclusion}

Given the needs of the students for mental health, we can provide them with intended comfort and intimacy according to the indexes considered for designing and building girl's hostel. In other words, mental/psychological health can be achieved by creating comfortable environment. With regard to the fact that comfort depends on security, it can be said that there is a mutual relationship between comfort and security; that is the more security increases, the better and the more ideal comfort we will reach. besides, the respondents' average scores on the elements of comfort such as availability and tall trees present the highest percentage in frequency distribution.

security depends on intimacy; there is a mutual relationship between various aspects of comfort and security. Therefore, the more intimacy increases, the more desired security can be achieved. The respondents' average scores on the elements of intimacy, including private/cozy corners, windows, building size and entrances suggest that corners among other elements in frequency distribution has the greatest impact on security and comfort. Considering the mentioned elements of comfort, other elements/indexes such as dormitory spatial connections and availability, open spaces for sports, tall trees in front of entrances or places that are intended to be protected from people's direct sight can increase dormitory security. We can reach a general perspective towards security and comfort in designing student's hostel if we observe the elements of intimacy for girl's hostel and pay attention to its indexes. In this way, we will create a place where students can gain ideal adaptability with their environment. In order to achieve intimacy in dormitories, the elements of comfort must be implemented along with plans approved by the designers. For example, easy and comfortable access can be considered and planned with regard to indirect place for connections such as corridors, and thus it can reach the spatial intimacy.

\section{Suggestions}

The results from the present research suggest the following strategies and procedures to improve the conditions of girl's hostel in terms of intimacy and comfort indexes.

1. If dormitory courtyard is not insight, planting trees can provide privacy/intimacy for the hostel. but this strategy cannot simply by useful and efficient for the dormitories whose courtyard is insight.

2. Enclosed courtyard in the middle of the dormitory can create intimacy.

3. Private corner should be out of sight; so, it can create to different levels inside the hostel and in the intended place.

4. There should be a place before each entrance, in this way, come for an intimacy can be maintained.

5. Some of the strategies for making to entrances private are taking advantage of trees and bushes, making the fracture in vision by changing the angle of arrival to the hostel, taking advantage of level difference to change the reactionary level of the pedestrians and students who stands in the hostels courtyard, and using additional light mesh walls.

6. To control visibility trough windows, we can used opaque, blared or sandblasted glasses. the latter case, that is sandblasted glass, can become and inspiring element for classes if it is painted and covered by geometric and arabesque motives.

7. Another ideal technique to create intimacy is using the hostel roofs and the open space where the students can spend their leisure. 
Hence, there is no need to tall walls, and intimacy can be provided by light and shorter walls.

\section{Refrences}

Everett, D, 87, loftus (zoll). “Resideut Assistauts as Rule

Hakim, B, S, (1969) Arabic Islamic cites: Bulding and planing priuciples (p.256). Routledge.

http:// pezeshk.us

http:// www.irma.ir/fa/news/view/liue.

Newell, D.B.(1995). Perspectives on privacy. Journal of Enironmental Psychology. 15, 87104.

Rousel, T, 8 R Elleven (2009). Im proving Resideut

Altman, Irwin, \& Chemers, M. (1984). Culture and Environment (First., p. 337). Cambridge University Press.

Tabrizi, Mostafa. 2000. Psychoanalysis of Living in Student's Dormitories. Monthly Payam-eZan. No 7

Hafeznia, Mohamad Reza. 2011. An Introduction to Research Methodology in the Humanities. Tehran: Samt Dey, The institute of the Study and Development of Human Science Academic Books.

Doctor Tousi, 1994. Student's Dormitories as Student's State, Jame-e-Salem Magazine. No 15

Rajabi, Abbas. Hijab and its Role in Mental Health, 2007. Center of Imam Khomeini Institute of Education and Research

Aliabadi, Mohammad et al. 2000. Studying Environment Psychological Indexes in Designing Student's Dormitories. Journal of Psychological Methods and Models. No 2.

Karimpur Fard, Mehrdad, 2007. Designing Student's Dormitories in Tehran District 22, Master Thesis/ Tehran University.

Mohamadi Farahran, Elham et al. 2012. Evaluating the Relationship between Quality of Sleep and Mental Health of Students Living in Dormitory. Quarterly of Danesh \& Tandorosti (Science and Health), Seventh Issue, No 3.
Jihad Deneshgi Research Deputy, Tehran Branch/2005. Designing Girl's Schools with Regard to Intimacy and Comfort.

Mahdavi nejad, Mohamad Javad, Mohammad Mashayekhi, 2010. The Needs for Designing Mosque Based on Socio-cultural Functions, Two Science-Research Journals of Armanshahr (Utopia), No 5.

Mirheydar, Mohsen, 1994. Student's Dormitories Design and Research Affairs, First Seminar on Student's Dormitories issues.

Mirheydar, Mohsen, 2001. Comparing Social and Cultural Conditions of the Family with Compatibility of the Students Residing in Alzahra University Dormitory.

Mirzaee, Soudabe, 2010 - 2011. Girl Student's Dormitory. Master Thesis, Islamic Azad University, Tafresh Branch.

Milanifar, Behrouz, 1995. Mental Health. Tehran: Ghos Publication. 